\title{
Cost-effectiveness analysis of antipsychotics in reducing schizophrenia relapses
}

\author{
Antonio J García-Ruiz ${ }^{1}$, Lucía Pérez-Costillas² ${ }^{2}$ Ana C Montesinos², Javier Alcalde³, Itziar Oyagüez ${ }^{4^{*}}$ and \\ Miguel A Casado ${ }^{4}$
}

\begin{abstract}
Background: Schizophrenia is a severe form of mental illness which is associated with significant and long-lasting health, social and financial burdens.

The aim of this project is to assess the efficiency of the antipsychotics used in Spain in reducing schizophrenia relapses under the Spanish Health System perspective.
\end{abstract}

Material and methods: A decision-analytic model was developed to explore the relative cost-effectiveness of five antipsychotic medications, amisulpride, aripiprazole, olanzapine, paliperidone Extended-Release (ER) and risperidone, compared to haloperidol, over a 1-year treatment period among people living in Spain with schizophrenia. The transition probabilities for assessed therapies were obtained from the systemic review and meta-analysis performed by National Institute for Health and Clinical Excellence (NICE).

Results: Paliperidone ER was the option that yielded more quality-adjusted life years (QALYS) gained per patient (0.7573). In addition, paliperidone ER was the least costly strategy (€3,062), followed by risperidone $(€ 3,194)$, haloperidol (€3,322), olanzapine (€3,893), amisulpride (€4,247) and aripiprazole $(€ 4,712)$. In the incremental cost-effectiveness (ICE) analysis of the assessed antipsychotics compared to haloperidol, paliperidone ER and risperidone were dominant options. ICE ratios for other medications were $€ 23,621 /$ QALY gained, $€ 91,584 / Q A L Y$ gained and $€ 94,558 /$ QALY gained for olanzapine, amisulpride and aripiprazole, respectively. Deterministic sensitivity analysis showed that risperidone is always dominant when compared to haloperidol. Paliperidone ER is also dominant apart from the exception of the scenario with a $20 \%$ decrease in the probability of relapses.

Conclusions: Our findings may be of interest to clinicians and others interested in outcomes and cost of mental health services among patients with schizophrenia.

Paliperidone ER and risperidone were shown to be dominant therapies compared to haloperidol in Spain. It is worthwhile to highlight that schizophrenia is a highly incapacitating disease and choosing the most appropriate drug and formulation for a particular patient is crucial.

The availability of more accurate local epidemiological data on schizophrenia would allow a better adaptation of the model avoiding some of the assumptions taken in our work. Future research could be focused on this.

Keywords: Schizophrenia, Relapse, Antipsychotic, Cost-effectiveness, Cost-utility, Spain

\section{Background}

Schizophrenia is a severe form of mental illness that has varying presentations. As a chronic disease, it is associated with significant and long-lasting health, social and financial burdens, not only for patients but

\footnotetext{
*Correspondence: ioyaguez@porib.com

${ }^{4}$ Pharmacoeconomics and Outcomes Research Iberia, De la Golondrina 40A, Madrid 28023, Spain

Full list of author information is available at the end of the article
}

for their families, other caregivers [1] and wider society $[2,3]$.

According to WHO estimates, schizophrenia affects approximately 24 million people worldwide [4]. The most recent publications estimate that the median incidence of schizophrenia varies from 15.2 [5] to 20.0 per 100,000 population/year [6], although it is higher in the 15 -35 year-old age group (7 per 1,000 population) $[7,8]$. There are no recent epidemiological data concerning

\section{空}


schizophrenia in Spain. Spain does not have a national registry that would make it possible to know the exact number of individuals with schizophrenia, although regional studies estimate the prevalence at $0.6-0.8 \%$ for the adult population (17 years of age and older) [9]. Available estimates from 1995 show that incidence of schizophrenia was 1.9 per 10,000 inhabitants per year for people between the ages of 15 and 54 years [10].

Conventional antipsychotic medications (chlorpromazine and haloperidol) emerged 50 years ago as the first tools on the management of schizophrenia, in concert with other important interventions, such as psychosocial and economic support and rehabilitation efforts. However, the unrivalled role of conventional antipsychotic medications has been continuously challenged by the wide range of adverse effects of these medications. Over the last 15 years, several new atypical antipsychotic medications have been introduced, including sertindole, risperidone, olanzapine, quetiapine, amisulpride, ziprasidone, aripiprazole and paliperidone [11]. In general, the new antipsychotics have shown themselves to be at least comparable in efficacy to conventional antipsychotics but with superior tolerability and a more favourable adverse effect profile, providing less extrapyramidal side effects than conventional treatment [8].

However, despite the availability of new antipsychotics, $20-30 \%$ of patients have an inadequate response to medication with $15-20 \%$ relapsing each year $[2,12]$. Compliance is one of the factors associated with relapse [13]; however, some patients relapse while taking maintenance medication [14].

Relapse has wider implications for the family in general, for the provision of medical and social facilities and from a health economic perspective [15]. In terms of quality of life, it has been shown to be associated with lower quality of life than in other stable medical conditions [16]. Onset of the disease in late adolescence or early adulthood [2] together with difficulties in employment and the social stigma associated with schizophrenia could be considered the main drivers of the changes in quality of life seen in these patients $[16,17]$.

Additionally, schizophrenia has been shown to place a substantial economic burden on both the health care system and society worldwide due to its potentially large demands on the healthcare system [18]. The full cost of schizophrenia is high, although this is rarely appreciated by health care decision makers or other stakeholders [3].

In Spain, drug's reimbursement is a central national decision. However, there is a strong territorial decentralization of health jurisdictions in the Autonomous Communities. Therefore, the final drug financing is an Autonomous Regions' responsibility covering almost $100 \%$ of population [19]. That means that caring of schizophrenia patients is covered by the public system. In the practice, schizophrenia is diagnosed and followed-up by a psychiatrist at a hospital level, after the patient is being referred by a general practitioner. First drug prescription is usually made by the specialist, but it is required that the patient attends to a primary care level asking for drug prescription in a funded way. In the global economic crisis environment we face, the efficient use of available healthcare resources is required to maximise health benefits for people with schizophrenia and, at the same time, reduce the emotional distress and financial implications of the condition to society [18]. Use of atypical antipsychotics could increase the total cost of the disease as a result of their relatively high price. However, their effectiveness results in reduced hospital stays, thus potentially decreasing total outlay. Indeed, these more expensive treatments could be cheaper for society in the long run [3]. The efficiency, understood as combined measure of efficacy and cost, of treatments for schizophrenia is one key parameter in the decision-making process [20].

Published economic evaluations suggest that atypical (second-generation) antipsychotics are cost-effective when compared with conventional (first-generation) therapy [21]. The aim of this project was to assess the efficiency of the antipsychotics used in Spain to reduce schizophrenia relapses under the National Health System perspective.

\section{Methods}

\section{Model design}

A decision-analytic model was developed using TreeAge software $\left({ }^{\odot} 2009\right.$ TreeAge Software, Inc. - Decision Analysis Software) to explore the relative cost-effectiveness of antipsychotic medications for people with schizophrenia in Spain. Figure 1 shows a schematic representation of the decision tree used.

The model compares oral amisulpride, aripiprazole, olanzapine, paliperidone Extended-Release (ER) and generic risperidone with generic oral haloperidol (primary comparator) in the treatment of patients with schizophrenia. Zotepine was discarded for not being marketed in our country.

According to the model structure, six hypothetical cohorts of people with schizophrenia in remission were initiated on each of the six oral antipsychotic medications assessed (first-line antipsychotic).

Patient could stop the first line antipsychotic when relapsing or due to the development of intolerable side effects and switch to a second line antipsychotic. People who stopped the first line antipsychotic for any other reason were assumed to do so abruptly and were moved to the no treatment group. These people remained without antipsychotic treatment until they experienced a relapse. People discontinuing treatment due to side 


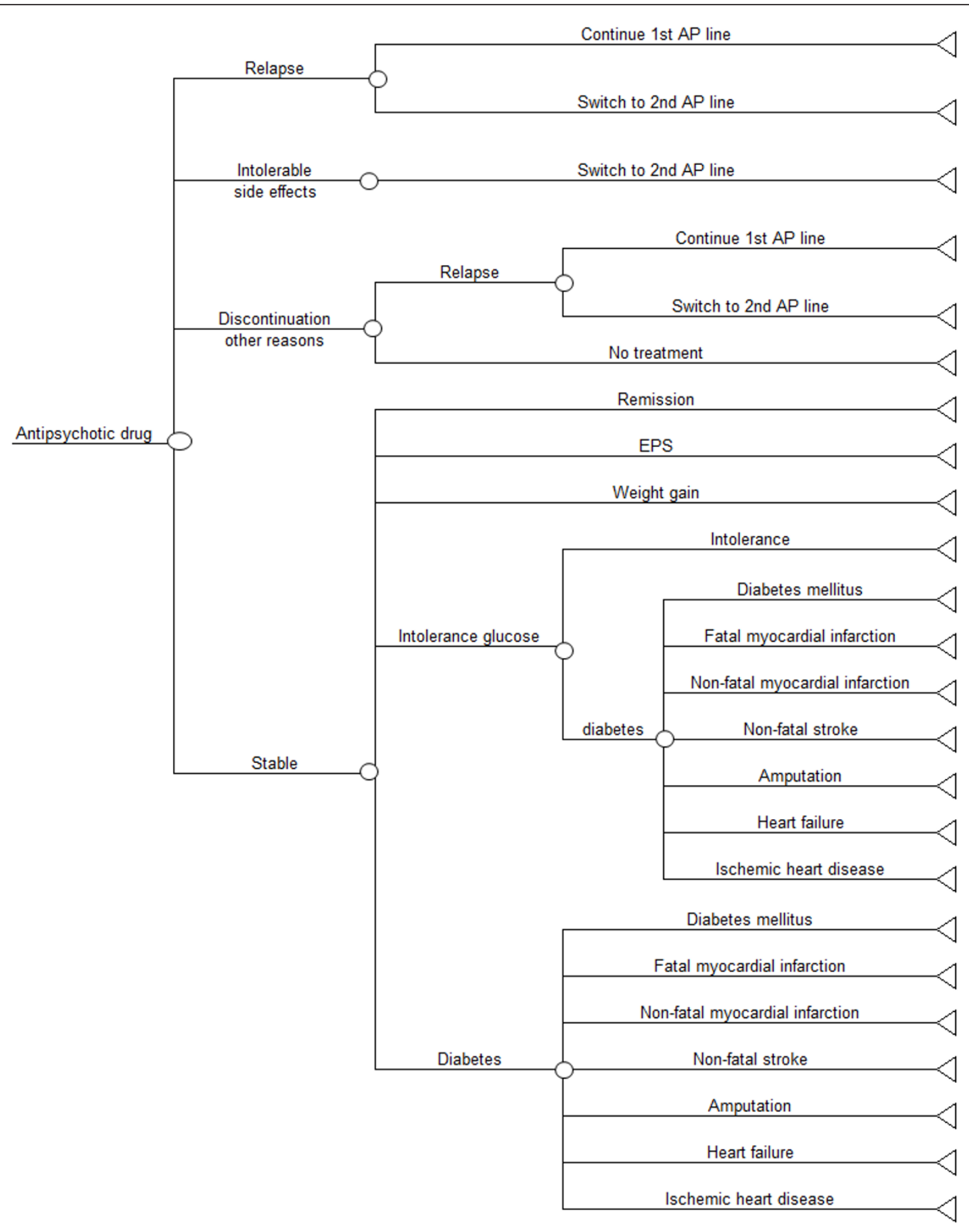

Figure 1 Schematic decision tree model for antipsychotic drugs in patients with schizophrenia.

effects or for other reasons were assumed not to experience relapse in the remaining time after the first line antipsychotic discontinuation occurred. All patients experiencing a relapse stopped any antipsychotic they had been receiving while in remission and were treated for the acute episode; after achieving remission, they either returned to their previous antipsychotic medication with the goal of promoting recovery (50\% of them) or switched to a second line antipsychotic drug (the remaining 50\%).

The first line antipsychotic described in the model structure was one of the six (amisulpride, aripiprazole, 
olanzapine, paliperidone ER or risperidone) oral antipsychotics evaluated in the analysis. The second line antipsychotic following the first line was haloperidol; the second line antipsychotic following haloperidol was olanzapine.

The model assessed the relative cost-effectiveness between the first line antipsychotics only. The purpose of incorporating medication switching in the model structure was to check the impact of the lack of effectiveness in relapse prevention (expressed by relapse rates), intolerance (expressed by discontinuation rates due to side effects) and unacceptability (expressed by discontinuation rates due to other reasons) of the first line antipsychotics on cost and health outcomes and to present a more realistic sequence of events related to treatment of people with schizophrenia with antipsychotic medication.

The model assumes that four types of side effects could be experienced by patients: extra-pyramidal symptoms (EPS) [22], clinically significant weight gain (increase in weight of at least $7 \%$ from baseline) and glucose intolerance or diabetes as a representative feature of the metabolic syndrome. It must be noted that acute EPS did not include cases of tardive dyskinesia $[9,23]$.

\section{Model probabilities}

Probabilities for each one of the assessed therapies were obtained from the systemic review and meta-analysis performed by NICE [18]. This systematic review was developed based on the results of 17 randomized clinical trials (RCT) including 3,535 subjects. All the analyzed RCTs provided information concerning the three main parameters considered in the economic model: relapse, treatment discontinuation due to side effects and treatment discontinuation for other reasons.

Table 1 details the probabilities used in the model. The probabilities that treatments are best in reducing relapse over 52 weeks were re-calculated from the probabilities used in the NICE model, with the exception of zotepine.

\section{Time horizon, perspective and discount rate}

The model was run from a third party payer perspective (National Health System) during a one-year timeframe. This period was chosen because clinical data on relapse on discontinuation were taken from trial lasting between 26 and 104 weeks. No robust evidence exists to confirm that extrapolation of effectiveness data reflects the longterm effectiveness of antipsychotic medication and its impact on the course of schizophrenia in real life.

The time horizon is less than one year thus no annual discount rate was applied [24].

\section{Cost-effectiveness analysis}

For each treatment, the average benefit in terms of Quality adjusted life year (QALY) gained and the average cost was calculated. The average cost-effectiveness ratio of each treatment was obtained.

Efficiency was established from the Incremental CostEffectiveness Ratio (ICER), defined as extra cost per QALY gained [25] with any of the antipsychotics versus haloperidol:

$$
\text { ICER }=\frac{(\text { Cost strategy } 1)-(\text { Cost haloperidol })}{(\text { Effectiveness strategy } 1)-(\text { Effectiveness haloperidol })}
$$

A strategy is considered as cost-effective versus haloperidol when ICERs are below the cost-utility threshold acceptable in Spain (€30,000/QALY gained) [26,27]

A strategy is dominant in comparison to haloperidol, when effectiveness (in QALYs) is higher, and cost is lower than the compared drug. In the same way, a strategy is dominated when effectiveness is lower, and cost is higher.

\section{Utilities}

To express outcomes in QALYs, the health states of the economic model needed to be linked to appropriate utility scores. Utility scores represent the HRQoL associated with specific health states on a scale from 0 (death) to 1 (perfect health); they are estimated using preference-based measures that capture people's preferences on, and perceptions of, HRQoL in the health states under consideration [18].

Utility scores for remission and relapse were derived from those published by Lenert et al [28]. Utilities for acute EPS and weight gain were calculated by multiplying the remission utility value by the expected decrement in utility reported by NICE ( 0.888 for acute EPS and 0.959 for weight gain) [18], which was estimated from the number of people endorsing the presence of each side effect, as reported in a paper by Lenert and colleagues [28].

Utilities owing to diabetes mellitus were taken from a national study carried out in Spain based on EQ-5D tariffs [29]. Utilities arising from complications from diabetes were also extracted from the literature [30]. Utility scores used in the model are detailed in Table 2.

\section{Cost estimation}

Costs considered in the model consisted of drug acquisition costs, inpatient stays due to relapse, outpatient primary and community care costs of treating adverse events and metabolic complications of antipsychotic treatment.

Patients under no treatment (following treatment discontinuation for reasons other than relapse or presence 
Table 1 Mean values of probabilities employed in the decision tree

\begin{tabular}{|c|c|c|c|c|c|c|c|c|c|c|c|c|c|c|}
\hline \multirow[t]{2}{*}{ Strategy } & \multirow[t]{2}{*}{$\begin{array}{l}\text { Probabilities } \\
\text { of relapse } \\
\text { over } 52 \\
\text { weeks }\end{array}$} & \multicolumn{2}{|c|}{$\begin{array}{l}\text { Probabilities of } \\
\text { discontinuation of } \\
\text { treatment over } 52 \\
\text { weeks }\end{array}$} & \multirow[t]{2}{*}{$\begin{array}{l}\text { Probabilities that } \\
\text { treatment is best in } \\
\text { reducing relapse over } \\
52 \text { weeks (reassessed } \\
\text { excluding zotepine) }\end{array}$} & \multicolumn{4}{|c|}{ Probabilities of adverse events } & \multicolumn{6}{|c|}{$\begin{array}{l}\text { Probabilities of Diabetes Mellitus } \\
\text { complications }\end{array}$} \\
\hline & & $\begin{array}{l}\text { Intolerable } \\
\text { side effects }\end{array}$ & $\begin{array}{l}\text { Other } \\
\text { reasons }\end{array}$ & & EPS & $\begin{array}{l}\text { Weight } \\
\text { gain }\end{array}$ & $\begin{array}{l}\text { Glucose } \\
\text { intolerance }\end{array}$ & $\begin{array}{l}\text { Diabetes } \\
\text { Mellitus }\end{array}$ & Amputation & $\begin{array}{l}\text { Fatal } \\
\text { myocardial } \\
\text { infarction }\end{array}$ & $\begin{array}{l}\text { Non-fatal } \\
\text { myocardial } \\
\text { infarction }\end{array}$ & $\begin{array}{l}\text { Non- } \\
\text { fatal } \\
\text { stroke }\end{array}$ & $\begin{array}{l}\text { Heart } \\
\text { failure }\end{array}$ & $\begin{array}{l}\text { Ischaemic } \\
\text { heart } \\
\text { disease }\end{array}$ \\
\hline Amisulpride & 0.2988 & 0.0554 & 0.2435 & 0.084 & 0.3163 & 0.3175 & 0.2381 & 0.0317 & 0.0023 & 0.0042 & 0.0130 & 0.0039 & 0.0040 & 0.0157 \\
\hline Aripiprazole & 0.2742 & 0.1582 & 0.3520 & 0.119 & 0.2258 & 0.1516 & 0.1167 & 0.0156 & & & & & & \\
\hline Haloperidol & 0.3317 & 0.0922 & 0.2516 & 0.035 & 0.5367 & 0.2000 & 0.1500 & 0.0200 & & & & & & \\
\hline Olanzapine & 0.1996 & 0.0783 & 0.2730 & 0.152 & 0.2336 & 0.4172 & 0.3129 & 0.0417 & & & & & & \\
\hline $\begin{array}{l}\text { Paliperidone } \\
\text { ER }\end{array}$ & 0.1625 & 0.3287 & 0.3848 & 0.525 & 0.2569 & 0.2123 & 0.1592 & 0.0212 & & & & & & \\
\hline Risperidone & 0.2761 & 0.0994 & 0.1761 & 0.086 & 0.3546 & 0.2141 & 0.1606 & 0.0214 & & & & & & \\
\hline
\end{tabular}

EPS: Extra-Pyramidal Symptoms)

ER: Extended-Release

Annual probability of transition of impaired glucose intolerance to diabetes $=0.0196$ 
Table 2 Utility scores

\begin{tabular}{|c|c|c|}
\hline Status & Utility value & Comments \\
\hline Remission & $0.799[28]$ & \\
\hline Relapse & $0.670[28]$ & \\
\hline $\begin{array}{l}\text { Acute EPS (extra-pyramidal } \\
\text { symptoms) }\end{array}$ & 0.7095 & $\begin{array}{l}\text { Calculated by multiplying remission utility by expected decrement in utilities estimated in the NICE } \\
\text { guidance [18] (0.888 for acute EPS and } 0.959 \text { for weight gain) }\end{array}$ \\
\hline Weight gain & 0.7662 & \\
\hline $\begin{array}{l}\text { Diabetes Mellitus } \\
\text { (controlled) }\end{array}$ & $0.760[29]$ & \\
\hline $\begin{array}{l}\text { Diabetes Mellitus } \\
\text { complications }\end{array}$ & $\begin{array}{l}\text { Disutility } \\
\text { value [30] }\end{array}$ & \\
\hline Amputation & -0.109 & \\
\hline Fatal myocardial infarction & 1.000 & \\
\hline Heart failure & $-0,108$ & \\
\hline Ischaemic heart disease & -0.132 & \\
\hline $\begin{array}{l}\text { Non-fatal myocardial } \\
\text { infarction }\end{array}$ & -0.129 & \\
\hline Non-fatal Stroke & -0.181 & \\
\hline
\end{tabular}

of intolerable side effects) were assumed to incur no costs until they experienced a relapse. Costs associated with baseline measurements and laboratory tests for monitoring purposes were omitted from the analysis, as they were estimated to be the same for all antipsychotic medications evaluated.

Drug acquisition costs were based on mean doses used as described by IMS (ICD codes F20) in Spain for each treatment (Table 3). Prices expressed in public prices (VAT included) per mg (price weighted by relative sales by put up) were obtained from the Pharmacist Official Council Catalogue [31].

The average cost of hospitalisation, including inpatient stay and pharmacological treatment for people experiencing acute episodes, was estimated from hospitalisation costs for people with schizophrenia, schizotypal and delusional disorders in Spain, from the disease-related group 430 (DRG-430, psychosis) [32]

Acute EPS management cost was the equivalent to one visit to the psychiatrist plus medication administered for the event (biperidene $2 \mathrm{mg} / 8 \mathrm{~h}$ during three months) [33]
Weight gain management cost was equivalent to one visit to a general physician every three months; this definition was based on expert opinion.

The cost of diabetes [34,35] and its complications (amputation [36], fatal myocardial infarction [37], heart failure [38], ischaemic heart disease [39], non-fatal myocardial infarction [37] and nonfatal stroke [40]) were obtained from literature.

\section{Unitary costs}

All costs were uplifted to 2009 prices, using appropriate price inflation rates [41]. The unitary costs detailed in Table 4 were obtained from the literature and from a Spanish database on health costs [42].

\section{Sensitivity analysis}

One-way deterministic analyses were carried out to test the model's robustness.

One-way deterministic analysis included modifications of the following inputs: relapse probabilities and treatment discontinuation probabilities (for adverse events or for other reasons) that were varied by $\pm 20 \%$.

Table 3 Acquisition costs of antipsychotic medications ( $€, 2009)$

\begin{tabular}{lllll}
\hline Strategy & Mean Daily Dose used $(\mathbf{m g})$ & Price/mg (included VAT in $€$ ) & Daily Treatment Cost $(€)$ & Annual cost $(€)$ \\
\hline Amisulpride & 611.12 & 0.0086 & 5.2556 & $1,918.31$ \\
\hline Aripiprazole & 15.42 & 0.4215 & 6.4995 & $2,372.33$ \\
\hline Haloperidol & 8.70 & 0.0356 & 0.3097 & 113.05 \\
\hline Olanzapine & 14.65 & 0.4382 & 6.4196 & $2,343.16$ \\
\hline Paliperidone ER & 6.40 & 0.8906 & 5.6998 & $2,080.44$ \\
\hline Risperidone & 5.39 & 0.5566 & 3.0001 & $1,095.03$ \\
\hline
\end{tabular}

ER: Extended-Release 
Table 4 Unitary cost $(€, 2009)$

\begin{tabular}{ll}
\hline Status & Cost $(\boldsymbol{€})$ \\
\hline Relapse (hospital cost) & $5,589(1)[32]$ \\
Acute EPS (extra-pyramidal symptoms) & $85(2)$ \\
Psychiatric medical visit & $68[42]$ \\
\hline Biperidene (2 mg/8 h/day) & $17[31]$ \\
\hline Weight gain & $117(3)$ \\
\hline General physician medical visit & $39[42]$ \\
\hline Diabetes Mellitus (control) & $855[34,35]$ \\
Amputation & $5,857[36]$ \\
Fatal myocardial infarction & $1,531[37]$ \\
Heart failure & $4,189[38]$ \\
Ischaemic heart disease & $2,474[39]$ \\
Non-fatal myocardial infarction & $21,610[37]$ \\
Non-fatal Stroke & $5,199[40]$
\end{tabular}

(1) = including inpatient stay and pharmacological treatment

(2) = including medication (biperidene $2 \mathrm{mg} / 8$ hours/day for three months) plus one medical visit to a psychiatrist

(3) = one visit to a general physician (primary care) for three months

\section{Results}

\section{Deterministic analysis}

Total cost per patient and effectiveness measured in QALYs for the six antipsychotic drugs assessed are shown in Figure 2. Paliperidone ER was the option that yielded more QALYs per patient (0.7573), followed by olanzapine (0.7475), aripiprazole $(0.7379)$, risperidone (0.7337), amisulpride (0.7333) and haloperidol (0.7232). In addition, paliperidone ER was the least costly strategy $(€ 3,062)$, followed by risperidone $(€ 3,194)$, haloperidol $(€ 3,322)$, olanzapine $(€ 3,893)$, amisulpride $(€ 4,247)$ and aripiprazole $(€ 4,712)$, in increasing order.

Average cost-effectiveness ratios of these antipsychotic medications are included in Table 5. Paliperidone ER had the lowest average cost-effectiveness ratio $(€ 4,043$ per QALY) and aripiprazole the highest (€6,386 per QALY)

\section{Incremental Cost-Effectiveness Ratio}

Figure 3 graphically represents the incremental costeffectiveness of assessed antipsychotics versus the primary comparator (haloperidol). Table 5 show ICERs of assessed antipsychotics versus haloperidol.

Paliperidone ER and risperidone yielded more QALYs and less cost than haloperidol Thus, they were considered dominant strategies, while haloperidol was a dominated strategy.

Considering the common threshold accepted in Spain (€30,000 per QALY gained) [27], olanzapine could also be considered a cost-effective option compared to haloperidol.

Both amisulpride and aripiprazole were above the threshold when compared with haloperidol.

\section{Sensitivity analysis}

Table 6 show details of the deterministic analysis performed. Risperidone is always a dominant strategy versus haloperidol. Paliperidone ER is also a dominant strategy over haloperidol apart from the scenario where basecase probability of relapse is reduced by $20 \%$, which yielded an ICER of $€ 1,687$ per QALY gained.

\section{Discussion}

To our knowledge, this analysis is the first economic evaluation assessing antipsychotics for prevention and treatment of schizophrenia relapses in Spain.

Atypical antipsychotics are cost-effective when compared with first generation antipsychotics (haloperidol), thus the expected higher acquisition cost of new antipsychotics are generally offset by reductions in other mental healthcare costs, particularly inpatient hospitalisation costs. This indicates that second-generation drugs may be a more efficient choice than traditional antipsychotics $[21,43]$.

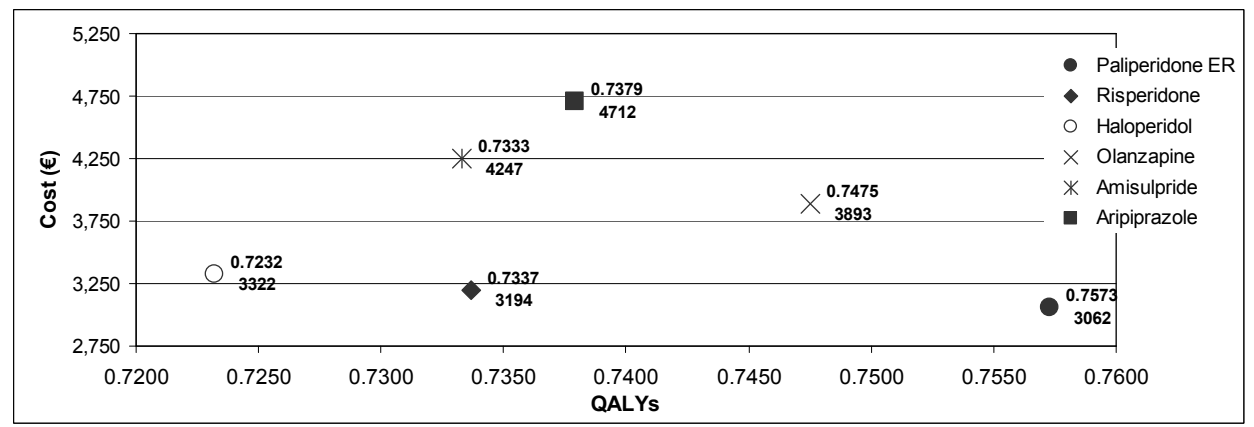

Figure 2 Cost-effectiveness of antipsychotics for relapse prevention. Data shown in the figure for each strategy refer to effectiveness in QALYs (upper value) and annual cost (€) (lower value). 
Table 5 Average cost-effectiveness (CE) and incremental cost-effectiveness (ICE) ratio of assessed antipsychotics versus haloperidol $(€, 2009)$

\begin{tabular}{lcc}
\hline Strategy & Average CE ratio $(€ /$ QALY) & ICE ratio $(€ /$ QALY gained) versus haloperidol \\
\hline Amisulpride & 5,792 & 91,584 \\
\hline Aripiprazole & 6,386 & 94,558 \\
\hline Haloperidol & 4,593 & $N A$ \\
\hline Olanzapine & 5,208 & 23,621 \\
\hline Paliperidone ER & 4,043 & Dominant \\
\hline Risperidone & 4,353 & Dominant
\end{tabular}

Dominant: strategy with higher effectiveness (QALYs) and lower cost

Our study showed lower average cost-effective ratios for paliperidone ER, risperidone and haloperidol than for olanzapine, amisulpride or aripiprazole.

In the base case of the present analysis, one year of treatment with paliperidone ER or risperidone compared with haloperidol were dominant strategies. Our results are in line with economic evaluations carried out by other investigators. Risperidone against haloperidol was also a dominant strategy in Canada [44] and had a lower risk of relapse [45]. Treatment with olanzapine resulted in higher costs than risperidone [46], but it was also cost-effective when compared with haloperidol in a Mexican study [47]. In the UK, despite equivalence with respect to the costs of three alternatives, both risperidone and olanzapine were cost-effective when compared with haloperidol due to efficacy gains [48].

Given that the willingness to pay for an additional QALY in Spain is generally estimated to be within the range of $€ 30,000$ to $€ 45,000$ [25,49] paliperidone ER and risperidone were identified as dominant therapies, olanzapine (€23,621 per QALY) could also be considered to be a cost-effective option versus haloperidol in the schizophrenia relapse treatment.

Modelling based on a decision tree to project 12month consequences of treatment for different antipsychotic therapies has been previously used in other economics evaluations [50].
As noted in NICE analysis, the key driver of cost effectiveness for antipsychotics is their probability to reduce relapse rates. Indeed, due to lack of head to head trials between the drugs analyzed, the current analysis is built on the mixed treatment comparison built on NICE based on retrospective available data.

The main drivers of the model are probabilities. Data from a systematic review performed by NICE were used, due to the lack of head-to-head trials between the drugs analyzed, although differences in relapse definition over the 17 studies included in this meta-analysis could lead to different relapse rates and potentially influence results.

The one-year treatment period was chosen because most of the clinical trials only assessed efficacy of antipsychotics in a 52-week period, and projection of the efficacy beyond 52 weeks would be a source of bias in the analysis. On the other hand, the last guideline for schizophrenia published by NICE considered a lifetime horizon given the potential need for long-term use of APS drugs by people with schizophrenia in remission.

The primary limitation of this evaluation was the omission of other antipsychotics, such as zotepine and quetiapine. As previously justified, zotepine was not included because it is not marketed in Spain. Quetiapine was also excluded due to the lack of relevant clinical information on this drug related to schizophrenia relapse prevention.

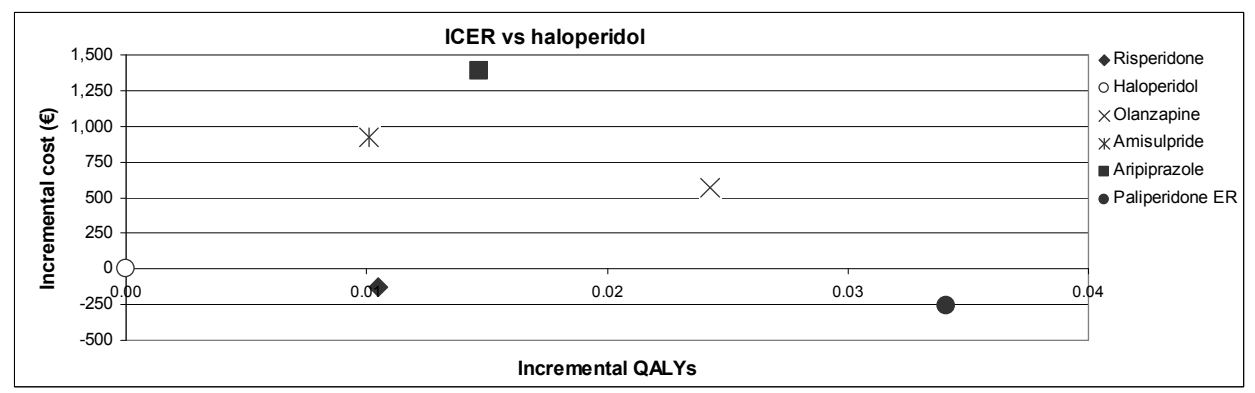

Figure 3 Incremental cost-effectiveness ratio (ICER) of assessed treatment options versus haloperidol. QALY: Quality-Adjusted Life Year. 
Table 6 Deterministic Sensitivity Analysis (ICERs of assessed antipsychotics versus haloperidol)

\begin{tabular}{|c|c|c|c|}
\hline Parameter & Incremental Cost $(€)$ & Incremental QALYs & ICER versus haloperidol (€/QALY gained) \\
\hline \multicolumn{4}{|l|}{ Base case (BC) } \\
\hline Amisulpride & 925 & 0.0101 & 91,584 \\
\hline Aripiprazole & 1,390 & 0.0147 & 94,558 \\
\hline Olanzapine & 574 & 0.0243 & 23,621 \\
\hline Paliperidone ER & -260 & 0.0341 & Dominant \\
\hline Risperidone & -128 & 0.0105 & Dominant \\
\hline \multicolumn{4}{|c|}{ Probability of relapse $+20 \% \mathrm{BC}$} \\
\hline Amisulpride & 795 & 0.0099 & 80,303 \\
\hline Aripiprazole & 1,227 & 0.0144 & 85,208 \\
\hline Olanzapine & 317 & 0.0258 & 12,287 \\
\hline Paliperidone ER & -632 & 0.0373 & Dominant \\
\hline Risperidone & -279 & 0.0107 & Dominant \\
\hline \multicolumn{4}{|c|}{ Probability of relapse $-20 \% \mathrm{BC}$} \\
\hline Amisulpride & 986 & 0.0150 & 65,733 \\
\hline Aripiprazole & 1,495 & 0.0131 & 114,122 \\
\hline Olanzapine & 773 & 0.0238 & 32,479 \\
\hline Paliperidone ER & 55 & 0.0326 & 1,687 \\
\hline Risperidone & -35 & 0.0099 & Dominant \\
\hline \multicolumn{4}{|c|}{ Probability of discontinuation due to $\mathrm{AE}+20 \% \mathrm{BC}$} \\
\hline Amisulpride & 861 & 0.0097 & 88,763 \\
\hline Aripiprazole & 1,356 & 0.0130 & 104,308 \\
\hline Olanzapine & 516 & 0.0238 & 21,681 \\
\hline Paliperidone ER & -287 & 0.0319 & Dominant \\
\hline Risperidone & -184 & 0.0099 & Dominant \\
\hline \multicolumn{4}{|c|}{ Probability of discontinuation due to $\mathrm{AE}-20 \% \mathrm{BC}$} \\
\hline Amisulpride & 930 & 0.0104 & 89,423 \\
\hline Aripiprazole & 1,373 & 0.0163 & 84,233 \\
\hline Olanzapine & 575 & 0.0249 & 23,092 \\
\hline Paliperidone ER & -291 & 0.0362 & Dominant \\
\hline Risperidone & -141 & 0.0114 & Dominant \\
\hline \multicolumn{4}{|c|}{ Probability of discontinuation due to other reasons $+20 \%$ BC } \\
\hline Amisulpride & 868 & 0.0094 & 92,340 \\
\hline Aripiprazole & 1,358 & 0.0135 & 100,593 \\
\hline Olanzapine & 490 & 0.0243 & 20,165 \\
\hline Paliperidone ER & -364 & 0.0349 & Dominant \\
\hline Risperidone & -211 & 0.0100 & Dominant \\
\hline \multicolumn{4}{|c|}{ Probability of discontinuation due to other reasons $-20 \% \mathrm{BC}$} \\
\hline Amisulpride & 923 & 0.0105 & 87,905 \\
\hline Aripiprazole & 1,363 & 0.0157 & 86,815 \\
\hline Olanzapine & 601 & 0.0242 & 24,835 \\
\hline Paliperidone ER & -213 & 0.0332 & Dominant \\
\hline Risperidone & -103 & 0.0106 & Dominant \\
\hline
\end{tabular}

Dominant: strategy with higher effectiveness (QALYs) and lower cost 
Although antipsychotic medication is associated with a wide range of adverse events, only EPS, weight gain and metabolic effects were considered in our evaluation, as they have been identified to be those with a greater impact on cost-effectiveness ratio.

Following a conservative approach, tardive dyskinesia was not included, despite its long-term and important effects on quality of life, as this event is mainly associated with the primary comparator (haloperidol). Including this side effect could introduce an important bias in the analysis [18].

The quality-adjusted life year (QALY) is routinely used as a summary measure of health outcome for economic evaluation, which incorporates the impact on both the quantity and quality of life [51] QALYs are obtained by multiplying life years gained by an utility value. Utilities represent patient's preferences by a health state, so they are strongly related to cultural aspects. Ideal economic evaluation would be based on data derived from local population where study is performed [52]. However publications with Spanish specific utilities values in the illness of interest are scarce. Although use of values from other areas could be a potential bias' source [53], in the present study, due to the lack of published data related to Spanish population, utilities from UK where used for remission, relapse, acute EPS and weight gain.

According the results from the deterministic sensitivity analysis developed, the model seems to be quite robust, but probabilistic sensitivity analyses would have provided additional information to validate this point.

Despite these limitations, the assumptions considered in the present model appeared to be reasonable and conservative, and the results of the sensitivity analyses indicated the robustness of the findings.

The current analysis shows that relapse prevention is the key driver for cost-effectiveness of antipsychotics in Spain. This conclusion is fully aligned with the results of the NICE analysis in the UK, which acknowledges that drug acquisition costs do not determine the relative cost-effectiveness of antipsychotic medications. Indeed, antipsychotic drugs that reduce the rate and duration of hospital admissions may be cost-saving options in the long-term, despite higher acquisition costs.

With respect to other Spanish studies, our results are also aligned with a previous analysis concerning the costs of schizophrenia in Spain, which showed that drugs account for only $24 \%$ of medical costs of the disease in Spain, whereas hospitalization accounted for $73 \%$ of those costs [54].

A previous investigation in Spain has shown that number of relapses is directly related to higher treatment costs [20]. The choice of the best alternative to reduce relapses, in efficacy terms, could indeed impact in the total schizophrenia cost. According our results paliperidone ER is the most effective and the least costly strategy.

Our findings may be of interest to clinicians and others interested in outcomes and cost of mental health services among patients with schizophrenia.

\section{Conclusions}

In our analysis, paliperidone ER and risperidone were shown to be dominant antipsychotic therapies compared to haloperidol in Spain. However, as pointed out by NICE, it is worthwhile to highlight that schizophrenia is a highly incapacitating disease and choosing the most appropriate drug and formulation for a particular patient is crucial. The prevention of relapses is a key factor in the efficiency of the antipsychotics.

\section{Author details}

${ }^{1}$ Catedra de Economia de la Salud y Uso Racional del Medicamento, Pharmacology and Clinic Therapeutic Department, University of Malaga, Malaga, Spain ${ }^{2}$ Carlos Haya General Hospital, Malaga, Spain ${ }^{3}$ Social Psychology Department, University of Malaga, Malaga, Spain

${ }^{4}$ Pharmacoeconomics and Outcomes Research Iberia, De la Golondrina 40A, Madrid 28023, Spain

\section{Authors' contributions}

AJG conceived of the study and performed a general coordination of the project. LP and ACM have made substantial contributions to conception and model design. LP, ACM and AJG have involved in acquisition of data and analysis. AJG, LP and AJG have played key role in interpretation of the results. $1 \mathrm{O}$ and MAC validated the assumptions taken in model design, reviewed the results, participating in interpretations of data, and were involved in drafting the manuscript. All the authors have participated sufficiently in the work to take public responsibility for appropriate portions of the content. All of them have reviewed the final version of the manuscript and have given a final permission of the version to be published. All authors read and approved the final manuscript.

\section{Competing interests}

This work was supported by an unrestricted research grant sponsored by Janssen-Cilag at Cátedra de Economia de la Salud y Uso Racional del Medicamento in University of Malaga The authors have not transmitted any conflicts of interest, because the concept, design and development of the model have been carried out independently.

$I O$ and MAC are PORIB employees a consultant company specialized in economic evaluation of health technologies.

Received: 19 December 2011 Accepted: 10 April 2012

Published: 10 April 2012

\section{References}

1. Awad AG, Voruganti LN: The burden of schizophrenia on caregivers: a review. Pharmacoeconomics 2008, 26(2):149-162.

2. Gee L, Pearce E, Jackson M: Quality of life in schizophrenia: a grounded theory approach. Health Qual Life Outcomes 2003, 1:31.

3. Knapp M, Mangalore R, Simon J: The global costs of schizophrenia. Schizophr Bull 2004, 30(2):279-293.

4. Piccinelli M, Gomez Homen F: Gender differences in the epidemiology of affective disorders and schizophrenia. Division of Mental Health and Prevention of substance abuse. Ed World Health Organization (WHO), Geneva; 1997 [http://www.who.int/mental_health/media/en/54.pdf], [accessed on November 12th, 2010].

5. McGrath J, Saha S, Chant D, Welham J: Schizophrenia: a concise overview of incidence, prevalence, and mortality. Epidemiol Rev 2008, 30:67-76.

6. Messias EL, Chen CY, Eaton WW: Epidemiology of schizophrenia: review of findings and myths. Psychiatr Clin North Am 2007, 30(3):323-338. 
7. Awad AG, Voruganti LN, Heslegrave RJ: Measuring quality of life in patients with schizophrenia. Pharmacoeconomics 1997, 11(1):32-47.

8. Awad AG, Voruganti LN: Impact of atypical antipsychotics on quality of life in patients with schizophrenia. CNS Drugs 2004, 18(13):877-893.

9. Allison DB, Casey DE: Antipsychotic-induced weight gain: a review of the literature. J Clin Psychiatry 2001, 62(Suppl 7):22-31

10. Vázquez-Barquero JL, Cuesta Nuñez MJ, de la Varga M, Herrera Castanedo S, Gaite L, Arenal A: The Cantabria first episode schizophrenia study: a summary of general findings. Acta Psychiatr Scand 1995, 91(3):156-162.

11. Tajima K, Hernández H, López-lbor JJ, Carrasco JL, Díaz-Marsá M: Tratamientos para la esquizofrenia. Revisión crítica sobre la farmacología y mecanismos de acción de los antipsicóticos. Actas Esp Psiquiatr 2009, 37(6):330-342.

12. Ayuso-Gutiérrez $J$, del Río Vega JM: Factors influencing relapse in the long-term course of schizophrenia. Schizophr Res 1997, 28(2-3):199-206.

13. Samalin L, Blanc O, Llorca PM: Optimizing treatment of schizophrenia to minimize relapse. Expert Rev Neurother 2010, 10(2):147-150.

14. Davies T: Psychosocial factors and relapse of schizophrenia Interventions with the families of schizophrenics can reduce relapse rates. BMJ 1994, 309:353-354.

15. Lader M: What is relapse in schizophrenia? Int Clin Psychopharmacol 1995, 9(Suppl 5):5-9.

16. Briggs A, Wild D, Lees M, Reaney M, Dursun S, Parry D, Mukherjee J: Impact of schizophrenia and schizophrenia treatment-related adverse events on quality of life: direct utility elicitation. Health Qual Life Outcomes 2008, 6:105

17. Marwaha S, Johnson S, Bebbington P, Stafford M, Angermeyer MC, Brugha T, Azorin JM, Kilian R, Hansen K, Toumi M: Rates and correlates of employment in people with schizophrenia in the UK, France and Germany. Br J Psychiatry 2007, 191:30-37.

18. NICE. National Institute for Health and Clinical Excellence. Schizophrenia: Core interventions in the treatment and management of schizophrenia in primary and secondary care (update). 2009 [http://www.nice.org.uk] National Clinical Practice Guideline Number 82. [accessed on November 12th, 2010].

19. Martín JJ, González Mdel P: The sustainability of the Spanish National Health System. Cien Saude Colet 2011, 16(6):2773-2782.

20. Vázquez-Polo FJ, Negrín M, Cabasés JM, Sánchez E, Haro JM, SalvadorCarulla L: An analysis of the costs of treating schizophrenia in Spain: a hierarchical Bayesian approach. J Ment Health Policy Econ 2005, 8(3):153-165.

21. Davies LM, Lewis S, Jones PB, Barnes TR, Gaughran F, Hayhurst K, Markwick A, Lloyd H, CUtLASS team: Cost-effectiveness of first- v. secondgeneration antipsychotic drugs: results from a randomised controlled trial in schizophrenia responding poorly to previous therapy. $\mathrm{Br} J$ Psychiatry 2007, 191:14-22.

22. Gray R, Gournay K: What can we do about acute extrapyramidal symptoms? J Psychiatr Ment Health Nurs 2000, 7(3):205-211.

23. Allison DB, Mackell JA, McDonnell DD: The impact of weight gain on quality of life among persons with schizophrenia. Psychiatr Serv 2003, 54(4):565-567

24. López-Bastida J, Oliva J, Antoñanzas F, García-Altés A, Gisbert R, Mar J, PuigJunoy J: Spanish recommendations on economic evaluation of health technologies. Eur J Health Econ 2010, 11(5):513-520.

25. Sacristán JA, Soto J, Reviriego J, Galende I: Farmacoeconomía: el cálculo de la eficiencia. Med Clin (Barc) 1994, 103:143-149.

26. Ortún V: 30.000 euros por AVAC. Econ Salud 2004, 17(49):1-2.

27. Sacristán JA, Oliva J, Del Llano J, Prieto L, Pinto JL: What is an efficient health technology in Spain? Gac Sanit 2002, 16:334-343.

28. Lenert LA, Sturley AP, Rapaport MH, Chavez S, Mohr PE, Rupnow M: Public preferences for health states with schizophrenia and a mapping function to estimate utilities from positive and negative symptom scale scores. Schizophr Res 2004, 71(1):155-165.

29. Mata Cases M, Roset Gamisans M, Badia Llach X, Antoñanzas Villar F, Ragel Alcázar J: Impacto de la diabetes mellitus tipo 2 en la calidad de vida de los pacientes tratados en las consultas de atención primaria en España. Aten Primaria 2003, 31(8):493-499.

30. Clarke P, Gray A, Holman R: Estimating utility values for health states of type 2 diabetic patients using the EQ-5D (UKPDS 62). Med Decis Making 2002, 22:340-349.
31. COF Consejo General de Colegios Oficiales de Farmacéuticos: Catálogo Nacional de Especialidades; [http://www.portalfarma.com].

32. MSPS Ministerio de Sanidad y Política Social: Explotación del registro de altas CMBD del Sistema Nacional de Salud.[http://www.msc.es/ estadEstudios/estadisticas/cmbd/informes/2007/ Categoria_Diagnostica_Mayor(CDM)/CDM019/GRD430/GRD430.html], [accessed on April 14th, 2010].

33. Departamento de Sanidad. Gobierno Vasco: Informe análisis de impacto presupuestario Paliperidona. 2009 [http://www.osanet.euskadi.net/r8520319/es/contenidos/informacion/farmacoeconomia/es_farma/fichas.html], [accessed on March 31st, 2011].

34. García AJ, Avila L, Gómez C, Montesinos AC: Direct cost for control of Diabetes Mellitus in a rural area. International Society for Pharmacoeconomics and Outcomes Research (ISPOR), 9th Annual European Congress Copenhaguen; 2006

35. García AJ, Morata F: Direct sanitary cost of diabetes control in a rural area. Quality of life. World Organisation for General Medicine (WONCA); European conference Paris; 2007.

36. Real Decreto $1247 / 2002$ de 3 de diciembre, por el que se regula la gestión del fondo de cohesión sanitaria. 2002, 290:42299-330[http:// www.boe.es/boe/dias/2002/12/04/pdfs/A42299-42330.pdf], BOE. [accessed on March 31st, 2011].

37. Levy E, Gabriel S, Dinet J: The comparative medical costs of atherothrombotic disease in European countries. Pharmacoeconomics 2003, 1:651-659.

38. Antoñanzas F, Anton F, Echevarria I, Juarez C: Clínica y epidemiología de la insuficiencia cardiaca congestiva (ICC): Un análisis de Costes. Clin Cardiovasc 1998, 16:27-34.

39. MSPS: Sistema Nacional de Salud, año 1997. Explotación de Bases del Conjunto Mínimo Básico de Datos Hospitalarios (CMBD) Madrid: Ministerio de Sanidad; 1997

40. Lamas J, Alonso M, Saavedra J, Garcia-Trio G, Rionda M, Ameijeiras M: Costes de la diálisis crónica en un hospital. público: mitos y realidades. Nefrologia 2001, 21:283-294.

41. INE. Instituto Nacional de Estadística. Sociedad: Nivel, calidad y condiciones de vida. Indice de Precios de Consumo.[http://www.ine.es].

42. Oblikue Consulting Base de datos sanitarios eSalud. [http://www.oblikue. com/bddcostes/], [accessed November 12th, 2010].

43. Gianfrancesco FD, Grogg AL, Mahmoud RA, Wang RH, Nasrallah HA: Differential effects of risperidone, olanzapine, clozapine, and conventional antipsychotics on type 2 diabetes: findings from a large health plan database. J Clin Psychiatry 2002, 63(10):920-930.

44. Oh Pl, Lanctot $\mathrm{KL}$, Mittmann N, Iskedjian M, Einarson T: Cost-utility of risperidone compared with standard conventional antipsychotics in chronic schizophrenia. J Med Econ 2001, 4:137-156.

45. Csernansky JG, Mahmoud R, Brenner R, Risperidone-USA-79 Study Group: A comparison of risperidone and haloperidol for the prevention of relapse in patients with schizophrenia. N Engl J Med 2002, 346(1):16-22, Erratum in: N Engl J Med 2002, 346(18):1424.

46. Vera-Llonch M, Delea TE, Richardson E, Rupnow M, Grogg A, Oster G: Outcomes and costs of risperidone versus olanzapine in patients with chronic schizophrenia or schizoaffective disorders: a Markov model. Value Health 2004, 7(5):569-584.

47. Palmer CS, Brunner E, Ruíz-Flores LG, Paez-Agraz F, Revicki DA: A costeffectiveness clinical decision analysis model for treatment of Schizophrenia. Arch Med Res 2002, 33(6):572-580.

48. Almond $\mathrm{S}, \mathrm{O}^{\prime}$ Donnell $\mathrm{O}$ : Cost analysis of the treatment of schizophrenia in the UK: A simulation model comparing olanzapine, risperidone and haloperidol. Pharmacoeconomics 2000, 17(4):383-389.

49. De Cock E, Miratvilles M, González-Juanatey JR, Azanza-Perea JR: Valor umbral del coste por año de vida ganado para recomendar la adopción de tecnologías sanitarias en España: evidencias procedentes de una revisión de la literatura. Pharmacoecon Sp Res Art 2007, 4:97-107.

50. Farahati F, Boucher M, Moulton K, Williams R, Herrmann N, Silverman M, Skidmore B: Overview of atypical antipsychotic monotherapy for schizophrenia: clinical review and economic evaluation of first year of treatment [Technology overview number 32]. Ottawa: Canadian Agency for Drugs and Technologies in Health; 2007.

51. Whitehead SJ, Ali S: Health outcomes in economic evaluation: the QALY and utilities. Br Med Bull 2010, 96:5-21. 
52. Barbieri M, Drummond M, Willke R, Chancellor J, Jolain B, Towse A: Variability of cost-effectiveness estimates for pharmaceuticals in Western Europe: lessons for inferring generalizability. Value Health 2005, 8(1):10-23.

53. Knies S, Evers SM, Candel MJ, Severens JL, Ament AJ: Utilities of the EQ-5D: transferable or not? Pharmacoeconomics 2009, 27(9):767-779.

54. Oliva-Moreno J, López-Bastida J, Osuna-Guerrero R, Montejo-González AL, Duque-González B: The costs of schizophrenia in Spain. Eur J Health Econ 2006, 7(3):182-188.

doi:10.1186/2191-1991-2-8

Cite this article as: García-Ruiz et al:: Cost-effectiveness analysis of antipsychotics in reducing schizophrenia relapses. Health Economics Review 2012 2:8.

\section{Submit your manuscript to a SpringerOpen ${ }^{\circ}$ journal and benefit from:}

- Convenient online submission

- Rigorous peer review

- Immediate publication on acceptance

- Open access: articles freely available online

- High visibility within the field

- Retaining the copyright to your article

Submit your next manuscript at $\gg$ springeropen.com 